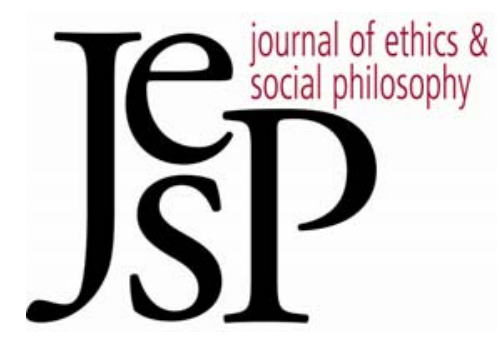

\title{
WHAT KNOWLEDGE IS NECESSARY FOR VIRTUE?
}

\author{
BY OLIVIA BAILEY
}

Journal of Ethics \& Social PhILOSOPhy

Vol. 4, No. 2 | FEBruary 2010 COPYRIGHT @ OLIVIA BAILEY 2010 


\title{
What Knowledge is Necessary for Virtue?
}

Olivia Bailey

\begin{abstract}
RISTOTELIAN ETHICS PRIDES ITSELF ON its close fit with the endoxa concerning how virtues are properly conceptual1 ized and invoked in our evaluation of agents. However, some critics contend that its picture of the virtues is, in reality, strikingly unrealistic. One version of this criticism that has proven to have considerable staying power is the argument that Aristotelianism demands too much of the virtuous person in the way of knowledge to be credible. This general charge is usually directed against either of two of Aristotelianism's apparent claims about the necessary conditions for the possession of a single virtue - namely that 1) one must know what all the other virtues require, and 2) one must also be the master of a preternatural range of techni$\mathrm{cal} /$ empirical knowledge. In this paper, I argue that Aristotelianism does indeed have a very high standard when it comes to the knowledge necessary for the full possession of a virtue, in both of these respects. However, I deny that this has unacceptable implications when it comes to the evaluation of moral agents. The demandingness of the ideal of full knowledge to which Aristotelianism is committed can be effectively counterbalanced by the recognition that some kinds of knowledge are much more important to various virtues than others are. Aristotelians and their critics alike tend to overlook this truth. Nevertheless, it has important implications for our evaluation of agents' virtuousness.
\end{abstract}

\section{The Reciprocity of the Virtues}

\section{a. The Problem}

The first of the aforementioned complaints about Aristotelianism's knowledge requirement is directed against what is commonly known as the "reciprocity of the virtues thesis," the thesis that the full possession of a single virtue requires the full possession of every virtue..$^{1,2}$ Before turning to the matter of why this notion has been so widely regarded as problematic or unrealistic, it is important to have some sense of what motivates it in the first place. In fact, the thesis is a necessary product of the combination of certain broader Aristotelian commitments. To illustrate why this is so, I turn to John McDowell's argument for the reciprocity of the virtues. Other Aristotelians have argued for the same conclusion in slightly different terms, but McDowell's version of the traditional

\footnotetext{
1 See Aristotle's statement to the same effect in the Nicomachean Ethics (at 1145a2-3).

2 This thesis is distinct from the "unity of the virtues" thesis associated with Socrates, which claims that knowledge of the good is sufficient for virtue and that all of the virtues really amount to the same thing, namely knowledge of the good. ${ }^{2}$ The root of the difference between the two is that, with Aristotelian reciprocity thesis, we are dealing with apt sensitivities (that is, motivationally attuned awareness) rather than simple possession of the facts about the thing to do. While the unity thesis is traditionally presented as the more aggressively intellectualist of the two, the reciprocity thesis is in reality less intellectualist only in the sense that it requires more than mere factual knowledge from agents.
} 
Aristotelian argument has the virtue of being relatively straightforward. ${ }^{3}$ What is more, it is frequently the particular target at which enemies of the reciprocity thesis choose to aim.

In brief, his argument runs as follows: virtue should issue in nothing but right conduct. But there will be cases in which different concerns, pertaining to what we think of as other virtues, must shape our recognition of what a particular virtue requires of us. I could not have the virtue of kindness without the virtue of justice, for instance, because there will be cases in which a lack of sensitivity to the demands of justice will prevent me from hitting the mark with regard to kindness. As the exercise of any one virtue will inevitably run into the concerns of the others - indeed as there are "no limits to the possibilities for compresence, in the same situation, of circumstances of the sorts proper sensitivities to which constitute all of the virtues" - the virtues are best thought of as bound inextricably together. ${ }^{4}$

I take it that McDowell does not deny that an expert in, say, courage could act without particular generosity on occasion without compromising the courageousness of his action. Not all virtues are relevant in all situations. Normally, it would be bizarre to say that the commander's being courageous in battle was contingent upon his hitting the target with regard to generosity in his action. The strength of the reciprocity of the virtues argument depends, rather, on the requirement that virtue be crosssituationally stable. Had the situation been different, had the need for generosity come into play, would the commander have known how that need would affect the proper realization of courage? If the answer is "No," then the commander cannot truly have the virtue. In assessing an agent's virtue we must appeal to such counterfactuals, rather than just the situations the agent happens to encounter, because Aristotelianism is ultimately concerned with the nature of a person's commitment to a virtue. Stability is a matter of having the ability to "get it right" in varying conditions, by virtue of the firmness of one's grasp of the demands the virtue makes, and just because one never actually finds oneself tested does not mean that one has the untested virtue.

The conclusion that one cannot really have a single virtue without having them all has struck even some authors generally sympathetic to virtue ethics as at best unrealistic and at worst "odious." " Even the individuals we think of as exemplars of particular virtues more often than not are obviously not virtuous in every respect. For example, Gandhi seems to have been unduly controlling of his sons' lives. ${ }^{6}$ Should we conclude, therefore, that he did not have the virtue of fortitude for which he is particularly admired? To do so would be highly counterintuitive. However, we seem to be pushed toward that admission as long as we accept McDowell's Aristotelian premises. Unless the reciprocity thesis can be

${ }^{3}$ For an alternative presentation, see e.g., Wolf (2007).

${ }^{4}$ McDowell $(1998,53)$.

5 Peter Geach (1977) cited in Kent $(1999,110)$.

${ }^{6}$ Carter $(1995,7)$. 
moderated, it appears, Aristotelianism will be left looking dramatically alienated from the endoxa in this respect.

\section{b. Weakening the Reciprocity Claim}

Gary Watson points out that the reciprocity thesis draws an unwarrantedly strong conclusion from the aforementioned premises. ${ }^{7}$ He notes that we can grant all of McDowell's premises and still conclude that, to possess a particular virtue fully, it is not necessary actually to have all of the other virtues fully as well. Rather, all that is needed is a certain level of sensitivity (intellectual and affective) to the other virtues. The possession of the virtue of generosity will often require that one be able to recognize what justice, kindness and other virtues demand, since these virtues can be simultaneously relevant in a whole variety of situations, but it is a leap from there to the conclusion that in order to possess the virtue of generosity, one must unfailingly have the proper understanding vis-à-vis justice, kindness, etc. in any situation whatever. A failure to grasp what these virtues entail exclusively in cases where generosity is irrelevant will in no way undermine the attribution of the full virtue of generosity.

Watson's point is a sound one, but it does not move us very far from the stronger presentation of the reciprocity thesis. As he admits, it would be strange if one had no grasp of kindness except in those cases where it was relevant to justice, so for the sake of psychological realism we must allow that the possession of a degree of reliable sensitivity relative to all potentially relevant virtues is necessary for the full possession of any one virtue, even though a slip in kindness when justice is not a salient consideration does not undermine one's claim to the latter virtue. Indeed, when one contemplates the variety of situations that require sensitivity to multiple virtues, it seems evident that if one is to possess a single virtue so perfectly that one could never miss the mark with regard to the relevant concern, one must be very far along the path toward having all of the other virtues. Commitment to the idea that a virtue must be backed by right understanding and motivation in the entire variety of possible circumstances continues to push us toward a "sublime" notion of what having a single virtue must entail.

\section{c. Attacking the Premises of the Argument for Reciprocity}

To escape the still-strong reciprocity thesis Watson's correction yields, some have tried attacking the premises of the McDowellian argument. It would be extremely difficult to deny the hypothetical compresence of circumstances calling for different virtues. Similarly, common sense is bound to cut short any attempt to argue that the ascription of a virtuous quality to someone does not require cross-situational stability. Prima facie, the premise that virtue yields only right action - what I will call the "success criterion" - seems a more vulnerable target.

7 Watson (1984). 
We could (following a critical route rather popular in the recent literature) assert that the success criterion does not capture our normal thinking about the relation between virtue and action, and should be replaced by a claim such as the following: virtues just get things right, calculatively, when it comes to achieving one's goals (whatever they may be), and normative rightness of action is not essential to virtue. That is, the "success" necessary for virtue consists only in effectively realizing one's aims, not in doing the morally correct thing. In this strategy's favor, it should be said that there is a set of virtues (the so-called "executive virtues," most notably temperance and courage) for which this solution is not obviously counterintuitive. Some people think that it is not at all wrong, but is in fact entirely natural or intuitively appealing, to say that a Nazi whose bravery makes him better able to act in line with his abhorrent ideals has the virtue of courage. Nevertheless, those who are happy to assert this all try to preserve some of what is ultimately a strong intuitive connection between virtue and normatively right action generally. Daniel Jacobson is less concerned than other recent commentators about honoring that link at the theoretical level, but even he attempts to enhance the plausibility of his allowing for brave, virtuous Nazis by asserting that the bravery makes its bearer more "admirable" and "good," though in a "limited sense" he declines to specify.8 Linda Zagzebski, arguing a line similar to Jacobson's, attempts to spell out this "sense." She contends that in this case the Nazi's ability to respond appropriately (in the calculative sense) to risks qualifies as a virtue, because even though it actually makes him worse, it nevertheless places him closer to the goal of moral excellence overall. A cellist who begins to learn the proper technique will at first sound worse, but with further education he will ultimately sound better than the person who stuck with the old, faulty method. Likewise, could we redirect the Nazi's bravery toward a morally appropriate cause, he would be more virtuous than a well-intentioned coward. ${ }^{9}$

The fact that the Nazi could hypothetically do the right thing had he different reasons, though, does not strike me as a sufficient reason to call his currently pernicious trait a virtue. One of the more important advantages the Aristotelian approach affords us is the chance to move beyond the basic binaries "good and bad," "right and wrong," in our assessments of character, in favor of more nuanced evaluations in terms of how far along the road to full virtue an agent is. As it stands, we can recognize and even admire to a degree elements of a merely naturally virtuous or even a habitually vicious person's character that may eventually contribute to his or her virtue, while still setting apart those who reliably do the right thing for the right reasons and with the right attitude as more excellent, more the type of person we should ultimately like to be, because more truly virtuous. However, if we set the standard of virtue such that traits that just may eventually contribute to right behavior (Zagzebski,

8 Jacobson $(2005,408)$.

9 Zagzebski (1996, 91-93). 
1996) or, similarly, just usually can be expected to issue in good consequences (Driver, 2001) are counted as virtues, then we must conclude one of two things. If we want to retain the thought that one's excellence does not vary independently of one's virtue, then we should conclude that (for example) unreliable or even vicious learners who tend to silence their fears and behave boldly are just as excellent with regard to matters of courage as the aforementioned superlative moral agents would be. This, however, is a highly unappealing move. Alternatively, we could conclude that the fact that the two aforementioned types both possess the virtue of courage simply does not translate into their being equally excellent. Now, there is no knockdown argument to the effect that drawing this latter conclusion is a worse option than allowing that the "brave" Nazi really is not courageous. Here, arguments must cede to intuition. But it seems to me that if we break the tight connection between degrees of actual excellence and degrees of actual virtue established by the success criterion, we will be out a concept useful for capturing a distinction between those who merely have attitudes that could be appropriate given better direction or sensitivity and those who actually get things right.

Virtue's intuitive connection with excellence is, I think, stronger than the feeling some people have that the Nazi should be described as brave. The latter naturally becomes more attractive if there is no way of making the reciprocity account, with which it is incompatible, more palatable. However, I will argue that if the reciprocity thesis is approached in the right way it need not end up looking unrealistic. Rather, it can serve to set a regulatory ideal compatible with the recognition that representing virtue as an all-or-nothing affair does not do justice to the nature of our ethical life.

\section{d. A “Cluster" Account of Virtues' Interrelation}

The first step toward a realistic account of virtues' interrelation must, I think, be a concession to everyday virtue attributions: we can maintain that minor (occasional or hypothetical) lapses of motivationally imbued knowledge do not defeat an agent's entitlement to the label "generous," "honest," etc., while also acknowledging that agents guilty of such faults do not possess the virtues completely. Softening the requirement for the assignation of a virtue label such that excellent reliability, and not absolute perfection, is required allows us to think of kind, or just, or courageous people as really existing. This squares not only with our everyday thinking but also with Aristotle's apparent treatment of phronimoi (the practically wise) as real. Moreover, this eliminates what would otherwise be an obvious difficulty with the counsel, common in virtue-ethical theory, to look to virtuous agents for guidance.

Obviously, "reliability" is a vague term. ${ }^{10}$ When, exactly, do we cease to be on our way to securing the label "kind" and actually arrive there?

10 Proponents of situationism, such as John Doris (2002), would argue that it is an inappropriate term when it comes to discussing virtue because our impression that some 
The question cannot be answered precisely. But we lose something when we focus solely on either the threshold of reliability or the threshold of perfection. The perfectionist ideal is a necessary product of the commitment to the tight connection between virtue and right action, so it is in one respect inescapable. We can also see why it might be a desirable element in a virtue ethical theory. It can serve to ward off complacency; with such an ideal on the horizon, one can see that there is always more moral work to be done. However, we also want our moral theory to account for our appreciation of the moral strengths of normal, non-ideal agents. So, while acknowledging the ideal of perfect knowledge and sensitivity, as well as the important achievement of reliability, we should turn our attention to the variety of actual agents on the road to virtue, with their practically inevitable foibles and gaps in experience. When we do, it will become clear that the relations between virtues are far more complex than either side on the debate over the reciprocity thesis has tended to acknowledge.

Arguing for the Watsonian reciprocity of the virtues, Rosalind Hursthouse writes that we are "surprised and often puzzled" when a person who does an exceptionally generous or courageous thing is found to have behaved in a morally repugnant fashion. ${ }^{11}$ Daniel Jacobson, conversely, declares himself surprised at Hursthouse's surprise.12 I suspect, though, that even two authors with intuitions as different as these would be more surprised to discover that a kind person behaved ungenerously than that an honest person did. When authors want to highlight the plausibility of the disunity thesis, they tend to refer to pairs such as temperance and courage, or (most frequently) justice and kindness. ${ }^{13}$ Advocates of the unity or reciprocity theses are then charged with explaining away the apparent conflicts inherent in these pairs. It is no accident, though, that these latter pairs are served up as evidence for the disunity thesis, in preference to other combinations of virtues such as generosity and kindness, or tolerance and forgiveness. I suggest that this is because the practical knowledge at the core of one virtue in the pairs courage/temperance and justice/kindness is relatively "far away" from that at the core of the other. Some virtues, by contrast, are "close" to each other. They tend to be cultivated together because they require similar attention and practice.

There are a few incidental mentions of what we might call "virtue clusters" in the literature. For instance, Christine Swanton refers to the "virtues of connoisseurship," though without specifying what these might be. ${ }^{14}$ But surprisingly, virtually no attention has been paid to what we might think of as the varied, uneven landscape of moral development in terms of groups of interrelated virtues. Insofar as authors do talk about

agents reliably act in ways that manifest classically sized virtues is mistaken. This is a serious charge, but it is not one I will address here.

${ }^{11}$ Hursthouse $(2002,55)$.

12 Jacobson $(2005,20)$.

13 See, e.g., Driver $(2006,143)$ and Walker $(1989,349-362)$.

14 Swanton $(2003,293)$. 
the acquisition of virtues by degrees, they tend to describe virtues as developing in step. ${ }^{15}$ Thomas Hurka does describe a kind of cluster of virtues, "the virtues of benevolence," in which he includes kindness and generosity. ${ }^{16}$ He does not mention them in the context of a discussion of patterns of virtue acquisition, but these virtues actually are a good example of "close" virtues with largely overlapping core knowledge requirements.

Hurka does not characterize it in exactly this way, since he treats the virtues of benevolence as "simple virtues" not delimited by proportionality, but it seems reasonable to say that someone well on the way to having the virtue of generosity must be finely attuned to the needs of others, with a giving spirit properly trained through experience. Kindness, similarly, involves an understanding of others' desires and feelings. The difference between it and generosity is that generosity involves freely giving some resource that is usually (in some sense) costly, whereas kindness is typically (but not always) more of an uncostly beneficence. Compassion is very like these two virtues in that it involves a desire to help, but it has specifically to do with experiencing others' suffering as bad. These virtues are all closely related in terms of the "direction" of the relevant motivation and subject of their understanding, since all three essentially require that the agent move beyond self-preoccupation in order to get a good sense of certain aspects of how others experience their situations. Extensive experience exercising the one, therefore, is highly unlikely to be independent of one's essential aptitude in the others.

Compassion, generosity and kindness are exceptionally close. Other virtues may be less tightly bound but still importantly linked. Honesty and justice, for instance, seem to be close in that a just person must be interested in what really is owed to whom, and honesty also critically involves respect for the value of the truth. Nevertheless, I think it is easier to imagine a person considerably advanced with regard to justice who nevertheless tends to tell small lies than it is to imagine a kind but notably uncompassionate individual. Further complicating the picture are still less obvious connections between individual virtues. Interestingly, even those virtues we tend to think of as practically opposed may each be close to certain virtues that are themselves not far apart. So, for instance, temperance is conceived of as the classic "cool" virtue, since it involves having the right attitude toward goods that should be enjoyed in moderation but in which we naturally tend to overindulge. Courage, conversely, is a "warm" virtue that involves having the right attitude toward situations from which people tend to shrink. But temperance surely shares a great deal in common with patience, as does courage with fortitude. And it seems reasonable to think that patience and fortitude are not far off from each other. They both critically involve knowing how to wait and how to

15 A.D.M. Walker (1989) is a notable exception; he relies on a developmental account to argue that some virtues are ultimately incompatible.

16 Hurka $(2001,106)$. 
look beyond one's immediate practical wants, and reliably exhibiting the one will generally require a good handle on the other.

Admittedly, identifying similarities and differences in the degree to which one possesses various of what we might call the "classic," mediumsized virtues risks obscuring a significant point: larger virtues may consist of smaller aspects and kinds, and these different kinds may bear different relations to other virtues. So (returning to generosity and kindness) while the generosity typically manifested in our relationships with friends involves sensitivity to needs, there may also be a more "distant" generosity that does not require sensitivity to the recipients' feelings. For example, a person who writes an appropriately large check to Oxfam each year does not need to have a particularly good sense of what the eventual recipients of his aid need, but it would be bizarre to deny that he is in a way generous, perhaps exceptionally so. ${ }^{17}$ The need for different sensitivities in order to realize different aspects of one classical virtue is illustrated particularly well by the virtue of courage, which even Aristotle thought to be best discussed in terms of types. Physical courage and social courage both critically involve the appropriate assessment of risk, but the kinds of risk they deal in (threat to one's physical wellbeing versus threat to one's reputation) are sufficiently different that connection between them may be more tenuous than that which brings different classical virtues close. One might be tempted, on the basis of such examples, to think of the traditional virtues as irrelevant, despite our common reference to them, and to focus instead on ever more narrow traits. ${ }^{18}$ Thinking about smaller virtues - virtues that are part of having courage or generosity overall - is a fine thing insofar as it contributes to the realism of our mapping of the virtues, but there are two important caveats. First, it seems sensible to say that reasoning and behaving appropriately just with regard to a very narrow, trifling concern should not be considered a virtue because it would trivialize the concept. As Neera Badhwar rightly asserts, generosity just when it comes to colored-button-sharing is not a virtue.19 Second, one of the things we admire about people who exemplify classical virtues is that they are able to apply their sensitivity well to a whole variety of situations, and we should not neglect the importance of this capacity in our haste to acknowledge how virtues like the ones Aristotle discusses can come apart. The classic virtues are not monolithic and indivisible, but this does not mean that they are in themselves unimportant.

Badhwar makes a suggestion that we might entertain as an alternative to thinking about virtues' interrelations in terms of their closeness across different scenarios. She suggests that we should focus on their simultaneous relevance within "domains" of concern, where domains are essentially psychologically isolable areas of practical concern in our lives, such

17 I am indebted to Roger Crisp for this example.

18 Doris $(2002,520)$. Doris contemplates the possibility of virtues such as compassionate-with-regard-to-helping-another-person-pick-up-papers-after-one-has-found-a dimein-a-phone-booth.

19 Badhwar (1996, 318). 
as that of the family and that of the career. In fact, she goes so far as to say that, while there is no global unity of the virtues, there is unity of the virtues within domains. She writes: "П] $\mathrm{f}$ is kind towards her friends and colleagues, she must also be generous, just, temperate, and courageous with respect to them." 20

Badhwar's theory captures something important about the interrelation of virtues. The idea that sensitivity to welfare concerns could vary wildly - depending solely upon whether justice concerns entered the picture - is psychologically unrealistic, as we noted in the discussion of Watson's proposal. It is easier to imagine that a person particularly committed to, say, her family would tend to have good sensitivity to the needs and feelings of its members, and so would "see" well what compassion, generosity and loyalty required in this domain - but would have less accurate perception with regard to these virtues when it comes to other groups to which she is less attentive. The particularity of our interests can therefore be part of a plausible story about the variability of our aptitudes.

That said, the idea of unity within a domain, spurred by one's particular dedication to that area of concern, needs to be understood in the context of two other observations. The first is that, in the stages of virtue acquisition before full virtue is reached, the same domain could harbor different levels of different virtues. While concern for, and practice responding to, a particular group is likely to contribute to the increasing sophistication of the virtues relevant to that sphere, this does not entail that all those intra-domain virtues need develop as one. In fact, in the earlier, less unified stages of acquiring virtue, the possession of one virtue to some imperfect degree may initially impede the development of another virtue within a domain. A moral beginner who is particularly motivated to be kind to his friends (but who has not yet grasped that sometimes kindness entails telling people truths that will be hard for them) may have more trouble being suitably honest with them than someone less kind. Tensions can spring up between imperfectly mastered elements of different virtues, and sometimes we will have to acquire a fairly sophisticated understanding of what a given virtue demands before our grasp of it ceases to grate against the requirements of other virtues, even though the virtues themselves are not opposed to one another. Secondly, as Badhwar acknowledges, "psychologically isolable" domains are porous when it comes to virtue. 21 For instance, doing the just thing when it comes to my friends may require an excellent understanding of the desserts of non-friends. This would be the case, for example, when I must decide how to distribute goods or blame between friends and nonfriends.

These observations support the impression that a realistic story of the development of virtue must not stop at the thought that people will tend to develop unified sets of virtues within particular domains. We can flesh out this story further through consideration of the relative closeness

20 Ibid., 308.

${ }^{21}$ Badhwar (1996, 318-319). 
of individual virtues at different stages of moral development, both within particular domains and without. Ultimately, Badhwar's insight that we will typically be further along with our virtues in some domains than others should not and need not be taken to replace or override observations concerning other connections between virtues - it is compatible with the cluster account I have been developing.

In conclusion, the utterly virtuous character will exemplify all the virtues to the same degree, but the virtues are not "equidistant" from each other. Knowledge of what certain other virtues require, and motivational sensitivity in relation to that knowledge, is of variable importance to a single virtue. We can affirm the hypothetical simultaneous relevance binding all of the virtues together, as well as the importance of maintaining appreciation for the concerns proper to a given virtue over a variety of situations, while also allowing that one might rightly be called "generous" even if one were not exceptionally honest, or "modest" even if one were not particularly loyal. Once we acknowledge this, the reciprocity of the virtues ceases to look incredible; it commits us to acknowledging an ambitious ideal, but not to denying that people can be far advanced with regard to some virtues while struggling with some others.

With this account of the reciprocity of the virtues in hand, I want now to turn to the other worry about the Aristotelian knowledge requirements for virtue that I flagged in my introduction. This is the concern that Aristotelianism sets an impossibly high standard of techni$\mathrm{cal} /$ empirical knowledge for the would-be possessor of virtue. Ultimately, my response to this criticism will mirror the one I have just developed in response to the reciprocity problem. I hope to show that like knowledge of what the other virtues require, technical/empirical knowledge is variably relevant to various virtues.

\section{Technical/Empirical Knowledge and Virtue}

The kind of non-technical knowledge about the needs and fears of others that I earlier highlighted as important for compassion, generosity and kindness is far and away the most talked about kind of knowledge when it comes to discussing the virtues. After all, contemporary proponents of Aristotelian ethics are quite rightly concerned to emphasize that practical wisdom is lived - a matter of emotional experience as well as good judgment. Practical wisdom is not essentially the ability to apply straightforward propositional knowledge through mechanical means-end reasoning. Virtue requires correct cognition, but this does not imply that the kind of knowledge we typically associate with intelligence (for example, an excellent vocabulary, or a good grasp of mathematical theorems) is the type most important to virtue. As Susan Wolf writes, "the requisite kind of knowledge [for virtue] has little to do with the kind that gets measured on IQ tests or the SATs." 22 Certainly, the relegation of this latter kind of knowledge to a role of lesser or even negligible importance in virtue has

22 Wolf $(2007,155)$. 
the blessing of intuition.

That said, however, the success criterion Aristotelianism builds into the concept of virtue does entail that the kinds of knowledge that tend to be applied instrumentally are also relevant to virtue. The virtuous action is the one that "hits the target" and, in order to hit the target, one must have an understanding of the situation that properly acknowledges all of its pertinent features. In reality, bodies of technical and empirical knowledge are sometimes relevant to that understanding. The boundaries of "technical" and "empirical" knowledge are of course loose. With regard to technical knowledge, though, I have in mind what we might think of as morally neutral techne, such as the knowledge of how to mix medicines or how to sculpt a statue. By "empirical knowledge," I mean general, nonmoral facts - some of which may be available to any rational agent capable of drawing the right inferences from available evidence, and others of which require more substantial investigation and experimentation to uncover.

Often, the empirical facts relevant to our success in exercising virtue are truths about human nature that we need to bring to bear on particular situations. An understanding of just how fallible and dependent human beings are, given our psychological and physical makeup, is important to forgiveness, to justice and also to modesty, for instance. However, having in hand facts about other subjects can also be important, and oftentimes this information is not the kind of thing we are simply bound to perceive. For instance, the recognition that even the lower animals can feel pain would (if true) be relevant to our full possession of various virtues, including compassion and, likely, respect, even though this is not the kind of knowledge that any reasonably observant person can just be expected to "pick up" without any investigative effort. ${ }^{23}$

Etiquette is an interesting example of virtue-relevant technical knowledge. Usually, it appears in the literature as contrasted with morality, in order to bring out the unique qualities of the latter. However, acting virtuously often will entail conveying one's sentiments and intentions effectively, and etiquette is not just about which utensils to use for which dish. Rather, it comprises the conventions of a culture governing proper expression, hence its importance for virtue: merely recognizing that someone is emotionally hurt, and being motivated to respond to that suffering, is liable to fall short of full virtue unless one knows the difference between culturally appropriate and culturally inappropriate means of conveying one's caring concern. Choosing a culturally inappropriate action (such as a "comforting" hug for a shomer negia of the opposite sex) could not only result in a failure to hit one's target with regard to the virtue, but also cause grave offence. ${ }^{24}$ Of course, sensitivity is still required for the virtuous use of etiquette. Sometimes, its rules should be overridden. And

23 The question of whether fish feel pain, for one, has been the subject of recent scientific controversy. See Sneddon et al. (2003).

24 A shomer negia is a person who observes the general prohibition (in Orthodox Judaism) against touching members of the opposite sex. 
it is also true that a person exceptionally well versed in such rules could be morally despicable. However, etiquette remains a discrete body of teachable knowledge that is important to some virtues.

Thus far, I have suggested that knowledge of biology and knowledge of social custom could both, on occasion, be important to acting virtuously. Further reflection in this vein would easily uncover other, similarly disparate subjects, knowledge of which could also be virtue-relevant. With so much potentially pertinent information, it makes sense to think that having the right knowledge about knowledge - that is, having a good sense of what information is needed to make the right decision, and what credence different sources should be given - is also important to virtue. Zagzebski argues that to appreciate all of the facts relevant to a moral decision in a given situation, one needs the intellectual virtues. For instance, honesty requires that one "take the trouble to be thorough and careful in weighing evidence." ${ }_{25}$ Hursthouse, similarly, points out that often, and particularly when faced with apparent dilemmas, our ability to choose virtuously depends upon an ability to identify the relevant facts in a situation where we are not in a position to acquire the details on our own and must rely upon others' reports. In such cases, we must use good inferential techniques to judge which of these reports are reliable. I would add to this list of potentially important "meta-knowledge" the knowledge of when to stop seeking more information. Sometimes, irrelevant facts can distract. Furthermore, certain virtues, such as impulsive courage and trust, require that the agent be able to judge well in scenarios where it would be inappropriate to seek out comprehensive information about a situation and/or person, even though that information could potentially contribute to her ability to avoid being harmed or betrayed. For instance, a virtuously trusting person would not commission a background check on a friend before deciding to tell the friend about her secret hopes and aspirations.

Zagzebski and Hursthouse's observations (as well as my addition, less directly) provide support for the general conclusion that the details any reasonable agent would be able to simply "read off' the appearance of a situation are not always enough to allow one to choose virtuously. Rather, one may also need to be able to investigate well (neither too much nor too little) and draw upon various general, empirical facts one has acquired. In actuality, the realization of some virtues may well in certain circumstances require the kind of inferential skills measured by standard intelligence tests.

\section{The Variable Relevance of Technical/Empirical Knowledge}

As the previous section established, cleverness is a part of practical wisdom, though it is not identical to it. Having allowed mundane knowledge and calculative ability an important role in practical wisdom, however, the question arises: exactly how much of this sort of knowledge do we need in

25 Zagzebski (1996, 159). 
order to be virtuous? Hursthouse makes the case that a person without a basic knowledge of first aid would be deficient in virtue because he or she would be incapable of saving an injured person where this would be the kind, just or otherwise virtuous thing to do. One's good intentions, absent the requisite technical knowledge, would not issue in right action. If we grant that she is right about the importance of knowing a basic firstaid technique such as CPR to full virtue, however, then what about a case in which success in saving a life would require knowledge of the more counterintuitive proper treatment for hypothermia?26 Or knowledge of how to perform a field amputation using a pocketknife?

Aristotelian virtue ethics excludes the person with good intentions but a grossly erroneous understanding of how to realize them from being virtuous and, this is not, I think, contrary to our normal understanding of virtue. Consider a hapless agent who, hoping to establish good relations with a blind adult, speaks to her using the simplified vocabulary he would normally employ in conversing with a child or takes her elbow to "guide" her without permission. Surely this agent is not as virtuous as a person who is more appropriately responsive to the blind person's intelligence and autonomy, even though the insensitive agent has his heart in the right place. When it comes to the possession of less commonsensical knowledge, however, the corresponding distinctions between levels of virtue that the Aristotelian approach seems to entail are less intuitively appealing. The association of complete virtue with the completely reliable selection of right action naturally yields the impression that to possess a single virtue completely we need to have what Terence Irwin calls an "encyclopaedic" knowledge of nonmoral facts. For Irwin, the success criterion creates a demand that even Aristotle would consider too high: Aristotle seems to think moral virtue is not concerned with the production typical of techne but, at the same time, his success criterion appears to demand the completely virtuous person "be a doctor or a plumber" (or, carrying the thought to its logical conclusion, both). ${ }^{27}$

It might seem that the best way out of this difficulty is to follow Hursthouse and Philippa Foot in affirming that the only knowledge required for or relevant to practical wisdom should be that which "anyone can gain in the course of an ordinary life." ${ }_{28}$ This would have happy consequences for typically kind, just, generous and/or generally virtuous people who do not know how to, say, perform open-heart surgery. And, furthermore, the solution does not amount to a mere affirmation that the knowledge we typically do acquire is all that can reasonably be expected of us. Hursthouse argues that knowledge of basic first aid is necessary for practical wisdom on the basis that it is reasonably easy to acquire and has a non-negligible chance of proving critical to success in doing the right thing, even though most people do not know it. Similarly, the fact that at

${ }^{26}$ Proper hypothermia treatment is counterintuitive insofar as one should not attempt to re-warm the victim by rubbing her skin or directly exposing her to intense heat sources. 27 Irwin $(1988,75)$.

${ }^{28}$ Foot $(2002,6)$. Cited in Hursthouse $(2006,306)$. 
one time slavery was not commonly known to be wrong does not mean that this knowledge needs to be discarded as necessary for complete virtue. Michael Slote worries that if we allow knowledge too great a role in what it means to have a virtue, we will be forced to conclude that our forbears could not have been virtuous. The ancient Greeks, for example, believed that slavery was morally acceptable and, for much of human history, women were not considered to have rights. ${ }^{29}$ This does not strike me as reason to be suspicious of the Foot/Hursthouse knowledge criterion, however. Once the difference between full and partial virtue is granted, the acknowledgment that our forbears had morally significant insensitivities does not commit us to the counterintuitive claim that none of them could be recognized as courageous, loyal and so forth.

The problem with simply accepting the "reasonable expectation" threshold - above which the possession of knowledge potentially relevant to success has no effect on a person's virtuousness - is that it is not obvious how it is to be squared with the connection Aristotelianism draws between virtue and success. While the threshold notion appeals to our intuitive sense that whether a person knows how to use a plumber's snake or not should have a negligible effect on her moral status, we still require a more substantial justification of this move. The Foot/Hursthouse solution includes no explanation of how its imposition of a "cut-off" does not undermine the whole force of the perfectionist orientation upon which the solution relies, up to a point. It does not reconcile the aforementioned intuition and the Aristotelian success/virtue connection.

This initially appealing proposal, then, proves unsatisfactory. That does not mean, however, that an acceptable resolution of the problem at hand is beyond reach. I suggest that we think about the importance of technical and empirical knowledge to virtues in the same way that I have urged we should think about the relevance to a single virtue of knowledge concerning what other virtues require. Some technical and empirical knowledge will be more relevant to achieving success overall, and some will be less. The relevance of various items of knowledge will also be variably relevant to different virtues. For any given virtue, an item of knowledge will be closer or further away from its "center."

So, for instance, one's knowing (and being properly mindful of) the depth of human fallibility is uncontroversially crucial to one's virtue overall. It is closer to the core of forgiveness and loyalty than it is to the heart of courage. Nevertheless, it is still more important to hitting the target reliably with regard to courage than, say, knowing how to cook well would be. It is not hard to imagine situations in which the courageous thing to do would require the former knowledge. For example, acting courageously in a given situation might entail forgiving someone who had wronged one, and proper awareness of the degree to which humans are subject to the vagaries of fortune could be essential to getting the forgiving right. If we were to really exercise our imaginations, we could un-

${ }^{29}$ Slote $(1982,74)$. 
doubtedly conjure up situations in which knowing how to cook well would be crucial to success in courage. Unlike the scenarios in which a proper awareness of human fallibility would be crucial to courage, however, scenarios in which knowing how to prepare, say, an impeccable duck a l'orange is integral to acting courageously would not be the kind of thing we would expect one to encounter over the course of a normal life. Situations in which items of knowledge are virtue-relevant that could reasonably be expected to arise in a normal human life, as opposed to hypothetically possible or actually realized situations, are of primary significance here. It might happen that knowledge concerning human fallibility is never called upon in an individual's life, but that life would have to be a strangely stunted one.

Technical and empirical knowledge take time to acquire, and some items of knowledge take a very long time to learn. Given the inevitable restriction posed by the human lifespan, it would be impossible, practically speaking, for one person to acquire all of the knowledge that could be relevant to achieving success in virtue. We can, however, retain complete knowledge as an ideal, thus preserving the connection between degrees of virtue and degrees of success without imposing a "cut-off" in the manner of Foot and Hursthouse. The crucial point is that, as we move outward from essential knowledge to more arcane, difficult-to-acquire knowledge, the importance to virtue of the knowledge in question diminishes.

The intuitive appeal of Foot and Hursthouse's notion of a threshold can, to a degree, be salvaged in a way compatible with the claim that increases in knowledge that could inform successful, virtuous action do not at a certain level cease to be relevant to our virtue ascriptions. I propose the following: an item of knowledge that is highly relevant to virtue and can be acquired without interfering unduly with the acquisition of other, equally or still more important items of knowledge is a piece of knowledge the possession of which will entail a considerable overall increase in one's ability to choose and execute right actions, and so it will significantly increase one's virtue overall. The sum of such items of knowledge represents a threshold important to our evaluation of agents' virtuousness. Above this threshold, the possession of additional virtue-relevant knowledge will still constitute an overall increase in virtue, but the increase will be much less important that that which results from addition of knowledge below the threshold. In terms of its implications for the assessment of agents' virtue, this is where my schema diverges from Foot and Hursthouse's. According to their views, there is no reason to think that someone who is in possession of all the knowledge that falls below the threshold plus (for example) knowledge of how to perform an emergency tracheotomy, is any more virtuous than the person who just meets the knowledge threshold. On my account, this is not the case. The first agent is more virtuous than the second. $\mathrm{He}$ is, after all, better equipped to achieve success than the second agent if placed in a situation where the virtuous thing to do is to save the life of a person who requires such an emergency procedure. However, the tracheotomy know-how is not highly 
important to any single virtue, or notably important to multiple virtues this is what places it above the threshold I have proposed. Consequentially, the difference in virtue between these two agents will be much less important than that between someone who knows the more essential truth about, say, human fallibility and one who does not.

Note that someone who knows how to perform an emergency tracheotomy may or may not be all-things-considered more virtuous for it; if taking the time necessary to acquire the skill were to prevent her from acquiring other knowledge more central to virtue, then she would be less virtuous overall than one who had used her time more wisely. This implies that wasting time pursuing less useful knowledge and skill when we could be learning something that would contribute more to our virtue is itself less than virtuous, even if this indulgence does not seem to harm anybody else. In a sense, then, the Aristotelian theory is very demanding when it comes to our knowledge-acquisition practices. The picture I have sketched does not deny this. It does, however, allow us to see how the maximally demanding ideal of the completely virtuous person, with complete technical and empirical knowledge, can be compatible with our feeling that there are very virtuous agents who lack various kinds of techni$\mathrm{cal} /$ empirical knowledge.

\section{Conclusion}

Initially, it looked as though taking the necessary connections between virtue, right action and knowledge seriously would mean admitting that no human agent could really be called "courageous" or "kind," let alone "virtuous in general." Even agents with what we would typically consider quite an extraordinary understanding of and sensitivity to, say, what courage requires could not be said to have the virtue if they lacked a similar sensitivity and understanding with regard to any other virtue. And, furthermore, it seemed that, even if an agent were to have a reasonable grasp of all of the virtues, he would also need to be in possession of all of the technical and empirical knowledge potentially relevant to the virtues in order to be truly virtuous. When the knowledge requirements for virtue are framed in this way, it seems obvious that Aristotelianism demands too much of agents in terms of understanding. However, when one gives the proper consideration to the fact that different kinds of knowledge are variably relevant to different virtues, it becomes clear that virtue is not an all-or-nothing prospect, and that one can be very virtuous without having all of the knowledge that Aristotelianism must require the ideally virtuous agent to possess.

Olivia Bailey

livi.bailey@googlemail.com 


\section{Bibliography}

Aristotle. Nichomachean Ethics. Trans. Irwin. Indianapolis: Hackett, 1985.

Badhwar, Neera. “The Limited Unity of Virtue.” Noûs. 30 (1996) 306-29.

Carter, April. Mahatma Gandhi: A Selected Bibliography. Westwood, CT: Greenwood Press, 1995.

Doris, John. Lack of Character: Personality and Moral Behaviour. Cambridge: Cambridge University Press, 2002.

Driver, Julia. Ethics: The Fundamentals. Oxford: Blackwell Publishing, 2006.

---. Uneasy Virtue. Cambridge: Cambridge University Press, 2001.

Foot, Philippa. Virtues and Vices and Other Essays in Moral Philosophy. Oxford: Oxford University Press, 2002.

Hurka, Thomas. Virtue, Vice and Value. Oxford: Oxford University Press, 2003.

Hursthouse, Rosalind. On Virtue Ethics. Oxford: Oxford University Press, 1999.

----. "Practical Wisdom: A Mundane Account." Proceedings of the Aristotelian Society. 106 (2006) 283-307.

Irwin, Terence. "Disunity in the Aristotelian Virtues." In Oxford Studies in Ancient Philosophy: Supplementary Volume. Ed. Annas. Oxford: Oxford University Press, 1988.

Jacobson, Daniel. "Seeing by Feeling: Virtues, Skills, and Moral Perception." Ethical Theory and Moral Practice. 8 (2005) 387-409.

Kent, Bonnie. "Moral Growth and the Unity of the Virtues." In Virtue Ethics and Moral Education. Ed. Carr and Steutel. London \& New York: Routledge, 1999.

McDowell, John. Mind, V alue and Reality. Cambridge, MA: Harvard University Press, 1998.

Slote, Michael. "Is Virtue Possible?” Analysis (1982) 70-76.

Sneddon L.U., Braithwaite V.A. \& Gentle M.J. "Do Fish Have Nociceptors: Evidence for the Evolution of a Vertebrate Sensory System." Proceedings of the Royal Society B 270 (2003) 1115-1122.

Swanton, Christine. Virtue Ethics: A Pluralistic View. Oxford: Oxford University Press, 2003.

Walker, A.D.M. "Virtue and Character." Philosophy. 64 (1989) 349-362.

Watson, Gary. "Virtues in Excess." Philosophical Studies. 46 (1984) 57-74.

Wolf, Susan. "Moral Psychology and the Unity of the Virtues." Ratio. 20 (2007) 145-167.

Zagzebski, Linda. Virtues of the Mind: An Inquiry into the Nature of Virtue and the Ethical Foundations of Knowledge. Cambridge: Cambridge University Press, 1996. 